\title{
Pengolahan Citra Digital Untuk Menghitung Ekstrasi Ciri Greenbean Kopi Robusta Dan Arabika (Studi Kasus: Kopi Temanggung)
}

\author{
Akhmad Fadjeri $^{1 \text { ) }}$; Arief Setyanto ${ }^{2)}$; Mei P. Kurniawan ${ }^{3)}$ \\ ${ }^{1)}$ Magister Teknik Informatika, Universitas Amikom Yogyakarta \\ 2) Magister Teknik Informatika, Universitas Amikom Yogyakarta \\ 3) Magister Teknik Informatika, Universitas Amikom Yogyakarta \\ ${ }^{1)}$ fadjeri.akhmadfadjeri@gmail.com; ' ${ }^{2}$ arief_s@amikom.ac.id ${ }^{2} ;{ }^{3}$ meikurniawan@amikom.ac.id ${ }^{3}$
}

\begin{abstract}
This study aims to determine the extraction of features in Robusta and Arabica green beans to make objects detectable and can be drawn into mathematical numbers. The method in this research is the original image is converted to RGB and grayscaling is carried out, then followed by a binary process aiming to change the image into binary form. After the digital image processing is complete, the process of extracting the characteristics of green coffee bean based on width, height, perimeter, surface area, roundness percentage, and perimeter in order to be understood mathematically. The results of the binary image process are carried out in morphological operations having an erosion and dilation process. The results of the erosion and dilation process are carried out the feature extraction to get the length, height, circumference, roundness ratio and perimeter of an image. Then, the value is stored in the database as a feature extraction of each green bean coffee. The result of feature extraction from green coffee bean samples shows a mean with 7.7 pixels' width, 11 pixels' height, 31.3 pixels' circumference, 69.5 pixels' surface area, 89,559 pixels' roundness percentage, and 1,674 pixels' perimeter of Robusta green bean. Meanwhile, Arabica green bean has 13.2 pixels' width, 18.8 pixels' height, 51.2 pixels circumference, 199.9 pixels' surface area, 94.548 pixels' percentage of roundness, and 1.600038 pixels' perimeter with 20 green coffee beans for the total of data.

Keywords: Digital Image Processing, Greenbean Coffee, Morphology, Feature Extraction
\end{abstract}

\section{PENDAHULUAN}

Pengolahan citra digital di era industri 4.0 memiliki fungsi yang sangat kompleks baik dalam bidang penelitian atau dunia teknologi informasi. Pemanfaatan citra digital telah banyak digunakan untuk mengidentifikasi sebuah obyek bentuk, dari yang berukuran kecil sampai berukuran besar. Pemanfaatan pengolahan citra digital salah satunya dilakukan untuk mendeteksi kematangan buah kopi dengan menggunakan dua fitur warna untuk mengetahui karakteristik kematangan buah kopi [1]. Penggunaan citra digital bisa diterapkan dalam menggambarkan penggunaan pemrosesan gambar (image processing) untuk mengenali tingkat panggang biji kopi digital dan mengklasifikasikan dengan Jaringan Saraf tiruan metode backpropagation [2]. Penelitian yang dilakukan Bambang Dwi Argo melakukan mengklasifikasi biji dan bubuk kopi robusta khas suatu daerah menggunakan NNPred dan memberikan informasi mengenai Artificial Neural Network (ANN) serta mengetahui parameter gambar terhadap biji dan bubuk kopi robusta khas suatu daerah [3]. Analisis yang berasal dari gambar untuk mendeteksi retak adalah dengan menggunakan teknik pemrosesan gambar yang disediakannya hasil yang akurat dibandingkan dengan metode manual konvensional [4] .
Pemanfaatan pengolahan citra digital dapat digunakan untuk mendapatkan ektrasi ciri sebuah greenbean kopi robusta dan arabika dengan menghitung perimeter, luas, panjang lebar, rasio kerampingan dan rasio kebulatan sebuah greenbean kopi.

\section{TINJAUAN PUSTAKA \\ 1. Citra digital}

Citra adalah gambaran visual mengenai suatu objek atau beberapa Objek. Tentu saja wujud citra dapat bermacam-macam, dari foto orang, gambar, hasil rontgen, hingga citra satelit. Menurut Abdul Kadir Jenis Citra di bagi menjadi tiga jenis yaitu citra biner (citra monokrom), citra berskala keabuan (grayscale), dan citra warna [5]. Sebuah citra digital dapat mewakili oleh sebuah matriks yang terdiri dari $\mathrm{M}$ kolom $\mathrm{N}$ baris, dimana perpotongan antara kolom dan baris disebut piksel ( piksel = picture element), yaitu elemen terkecil dari sebuah citra. Piksel mempunyai dua parameter, yaitu koordinat dan intensitas atau warna. Nilai yang terdapat pada koordinat $(x, y)$ adalah $f(x, y)$, yaitu besar intensitas atau warna dari piksel di titik tersebut. Sebuah citra digital dapat ditulis dalam bentuk matriks berikut 


$$
f(x, y)=\left[\begin{array}{cccc}
f(0,0) & f(0,1) & \ldots & f(0, M-1) \\
f(1,0) & \ldots & \ldots & f(1, M-1) \\
\ldots & \ldots & \ldots & \ldots \\
f(N-1,0) & f(N-1,1) & \ldots & f(N-1, M-1)
\end{array}\right]
$$

Berdasarkan gambaran tersebut, secara matematis citra digital dapat dituliskan sebagai fungsi intensitas $f(x, y)$, dimana harga $x$ (baris) dan y (kolom) merupakan koordinat posisi dan $f(x, y)$ adalah nilai fungsi pada setiap titik $(x, y)$ yang menyatakan besar intensitas citra atau tingkat keabuan atau warna dari piksel di titik tersebut. Pada proses digitalisasi (sampling dan kuantitas) diperoleh besar baris $\mathrm{M}$ dan kolom $\mathrm{N}$ hingga citra membentuk matriks $\mathrm{M} \times \mathrm{N}$ dan jumlah tingkat keabuan piksel [6] .

\section{Pengolahan Citra Digital}

Pengolahan citra atau Image Processing adalah proses memperbaiki gambar citra agar mudah di olah oleh manusia/mesin (komputer). Masukan dari citra adalah citra dan keluarannya juga citra tapi dengan kualitas lebih baik dari pada citra input, misal citra warnanya kurang tajam, kabur (blurring), mengandung noise (misal bintikbintik putih) [6]. Berdasarkan nilai pikselnya, citra digital dapat dikelompokan kedalam tiga jenis citra, yaitu:

\section{Citra Warna}

Citra warna atau Model warna RGB adalah model warna aditif di mana merah, hijau dan biru ditambahkan bersama dalam berbagai cara untuk membuat beragam warna. Nama model berasal dari inisial dari tiga warna utama merah, hijau dan biru. Tujuan utama model warna RGB adalah untuk penginderaan, representasi dan tampilan gambar dalam sistem elektronik, seperti televisi dan komputer, meskipun juga sudah digunakan dalam fotografi konvensional [7].

\subsection{Citra grayscale}

Citra berskala keabuan (grayscale) adalah citra menggunakan gradasi warna abu-abu yang merupakan kombinasi antara hitam dan putih. Setiap warna di dalam citra berskala keabuan dinyatakan dengan sebuah nilai bulat antara 0 dan 255 (untuk yang aras keabuannya $=256$ ) dan nilai tersebut disebut sebagai intensitas [5].

\subsection{Citra biner}

Citra biner adalah proses untuk mendapatkan bagian gambar tingkat keabuan yang memiliki dua nilai keabuan, nilai 0 untuk hitam dan 1 untuk putih, sehingga setiap pixel dari gambar biner adalah selalu dikodekan dengan nilai 1 [8]. Gambar biner yang dihasilkan dari konversi menjadi hitam dan putih akan diproses ulang untuk mendeteksi lokasi objek yang dianggap untuk menghilangkan nilai piksel kecilnya [8].

Secara umum, proses pengambangan citra grayscale untuk menghasilkan citra biner adalah sebagai berikut:

$(x, y)=\{1$ jika $f(x, y) \geq T 0$ jika $f(x . y)<T\}$

dengan $g(x, y)$ adalah citra biner dari citra grayscale $\mathrm{f}(\mathrm{x}, \mathrm{y})$ dan $\mathrm{T}$ menyatakan nilai ambang. Kualitas citra biner yang dihasilkan sangat tergantung pada nilai T yang digunakan [9].

\section{Preprosesing}

Preprocessing adalah penyesuaian ukuran citra untuk mendapatkan Region of Interest (Rol) dan peningkatan kualitas citra [10]. Pada tahap preprocessing terdapat pemrosesan data gambar yang meningkatkan variasi gambar dengan memanipulasi mereka dalam beberapa cara seperti membalik, mengubah ukuran, dan acak memotong [8].

\section{Morfologi}

Morfologi secara sederhana dapat diartikan sebagai bentuk dan struktur suatu objek atau dalam deskripsi lain susunan dan hubungan antar bagian pada suatu objek [11]. Dilasi adalah Bila suatu objek (citra input) dinyatakan dengan A dan SE dinyatakan dengan $B$ serta $B x$ menyatakan translasi $B$ sedemikian sehingga pusat $B$ terletak pada $x$. Operasi dilasi A dengan B dapat dinyatakan sebagai berikut.

Rumus Dilasi [9].

$D(A, B)=A \oplus B=\{x: B x \cap A \neq \emptyset\}$

$\emptyset$ menyatakan himpunan kosong.

Proses dilasi dilakukan dengan membandingkan setiap piksel citra input dengan nilai pusat SE dengan cara melapiskan (superimpose) SE dengan citra sehingga pusat SE tepat dengan posisi piksel citra yang diproses. Jika paling sedikit ada 1 piksel pada SE sama dengan nilai piksel objek (foreground) citra. maka pixel input diset nilainya dengan nilai piksel foreground dan bila semua piksel yang berhubungan adalah background maka input pixel diberi nilai pixel background. Proses serupa dilanjutkan dengan menggerakan (translasi) SE pixel demi piksel pada citra input. 


\section{Ekstrasi Ciri}

Ekstrasi ciri diperoleh melalui perhitungan deskriptor bentuk regional sederhana yaitu perhitungan area, perimeter untuk compactness, major axis length, minor axis length, dan aspek rasio lebar dan tinggi. Pada citra biner digital, area didefinisikan sebagai jumlah piksel yang berada di dalam region. Area juga didefinisikan sebagai luas dari suatu objek. Perimeter atau keliling menyatakan panjang tepi suatu objek. Compactness menyatakan perbandingan perimeter kuadrat dan area [12].

\section{Perhitungan Perimeter}

Perimeter (keliling) menyatakan panjang dari kerangka yang dihasilkan. Perimeter di hitung dengan rumus sebagai berikut.

$P=$ jumlah kode genap $+\sqrt{2}$. jumlah kode ganjil

\section{Perhitungan Luas area}

Berdasarkan kode rantai dapat dinyatakan sebagai berikut

$$
\begin{array}{ll}
\text { kode } 0 & : \text { Area }=\text { Area }+\mathrm{Y} \\
\text { kode } 1 & : \text { Area }=\text { Area }+(\mathrm{Y}+0.5) \\
\text { kode } 2 & : \text { Area }=\text { Area } \\
\text { kode } 3 & : \text { Area }=\text { Area }-(\mathrm{Y}+0.5) \\
\text { kode } 4 & : \text { Area }=\text { Area }-\mathrm{Y} \\
\text { kode } 5 & : \text { Area }=\text { Area }-(\mathrm{Y}-0.5) \\
\text { kode } 6 & : \text { Area }=\text { Area } \\
\text { kode } 7: \text { Area } & =\text { Area }+(\mathrm{Y}-0.5)
\end{array}
$$

\section{Rasio Kebulatan}

Kebulatan bentuk adalah perbandingan antara luas objek dan kuadrat perimeter, yang dinyatakan dengan rumus seperti berikut:

Kebulatan $(\mathrm{R})=4 \pi \frac{A(R)}{p^{2}(R)}[14]$.

\section{METODE PENELITIAN 1. Objek Penelitian}

Penelitian ini menggunakan 2 jenis greenbean kopi Temanggung yang sudah dilabeli berdasarkan standarisasi kopi nasional, yaitu greenbean kopi arabika dan greenbean kopi robusta. Gambar atau citra dari greenbean kopi sebagai masukan dalam sistem yang akan dibuat. Penelitian ini menentukan citra masukan yang akan menghasilkan suatu keluaran berupa ekstrasi ciri dari greenbean kopi. Dengan adanya sistem ini, diharapkan dapat memberikan informasi dalam bentuk greenbean kopi berdasarkan pengolahan citra digital. Bahan yang digunakan dalam penelitian adalah 2 jenis biji kopi.

\section{Alur Penelitian}

a. Penelitian di mulai dengan survey ke lokasi kebun kopi untuk mendapatkan informasi greenbean kopi arabika dan robusta di Temanggung.

b. Setelah greenbean telah diketahui label jenisnya kemudian dilakukan pengambilan gambar/ foto pada setiap jenisnya.

c. Gambar greenbean yang masih memiliki resolusi besar sesuai resolusi foto kemudian dilakuan cropping dengan rasio $32 \times 32$. Hasil cropping masih berupa citra warna (RGB) diubah menjadi citra grayscale. $\mathrm{Hal}$ ini dimaksudkan agar tiap piksel citra RGB yang mempunyai tiga nilai kanal dapat disederhanakan menjadi hanya satu kanal saja pada citra grayscale.

d. Citra grayscale kemudian diubah menjadi citra biner untuk memisahkan objek dengan latar belakangnya. Hal ini juga dilakukan untuk persiapan operasi morfologi citra pada tahap selanjutnya.

e. Operasi morfologi yang pertama dilakukan pada citra biner adalah dilasi. Ini dilakukan untuk menghilangkan objek-objek kecil yang tidak akan diproses lebih lanjut. Kemudian, dipilih objek yang akan dihitung luasnya sehingga pada citra biner hanya ada objek yang diinginkan. Tahap selanjutnya melakukan perhitungan, Perimeter, luas, lebar, tinggi, rasio kebulatan. Alur penelitian ditunjukkan pada Gambar 1.

\section{Akuisisi Data}

Biji kopi yang telah di labeli secara manual kemudian dilakukan proses akuisisi data citra biji kopi menggunakan kamera digital Cannon 1100, bidang putih sebagai background dalam pengambilan foto citra biji kopi dan lampu sebagai pencahayaan. Proses akuisisi ini dilakukan dengan meletakkan satu persatu biji kopi di atas bidang putih, kemudian mengatur cahaya lampu agar sama serta jarak kamera digital dengan objek $19 \mathrm{~cm}$. Pada proses ini menghasilkan 110 gambar dengan masing masing kelas sebanyak 20 gambar. Citra hasil akuisi disimpan dalam format *jpg. Ilustrasi akuisisi data ditunjukan pada Gambar 1. 


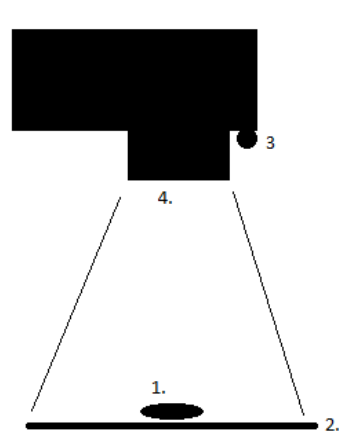

Gambar 1. llustrasi Proses Akuisisi Citra

\section{HASIL DAN PEMBAHASAN}

\section{Hasil Survey Lapangan}

Penelitian ini dimulai dengan survey ke lapangan untuk mendapatkan informasi greenbean yang ada di Kabupaten Temanggung. Hal ini dilakukan untuk memperoleh informasi tentang jenis kopi yang hidup di daerah perkebunan kopi. Peneliti mendapatkan informasi 2 jenis kopi seperti yang diharapkan. Peneliti mendapatkan informasi perbedaan dari bentuk biji kopi yang berbeda dari greenbean arabika dan robusta.

Setelah mendapatkan sampel greenbean kopi, peneliti melakukan pengambilan gambar greenbean jenis arabika dan robusta untuk selanjutnya dilakukan pemrosesan citra digital dan perhitungan perimeter, luas area, panjang, lebar, dan rasio kebulatan dari kedua jenis greenbean. Skema pengambilan gambar diilustrasikan pada Gambar 2.

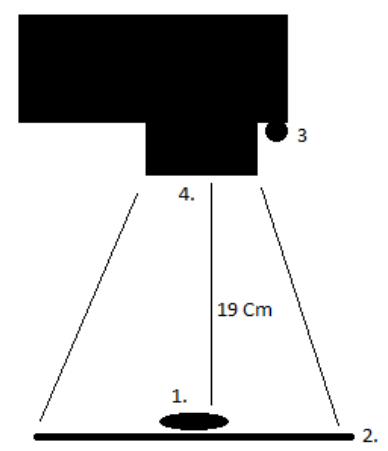

Gambar 2. Skema Pengambilan Gambar

Tabel 1. Hasil Foto Greenbean Kopi

\begin{tabular}{|c|c|c|l|}
\hline No & Depan & Belakang & Jenis Kopi \\
\hline 1 & & & Arabika \\
& & & \\
\hline
\end{tabular}

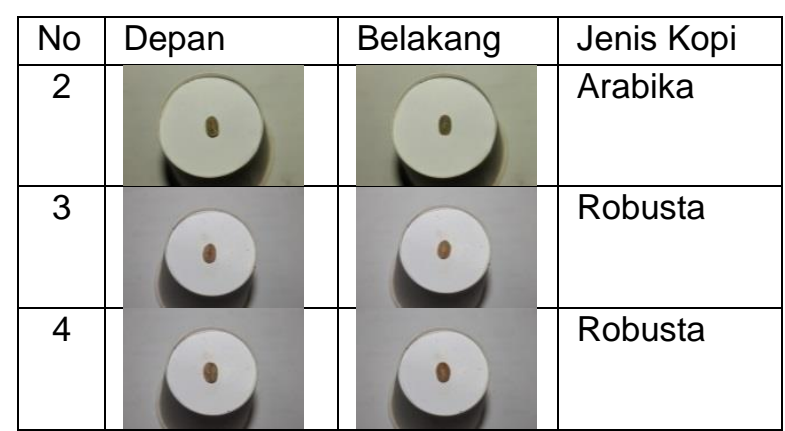

2. Tahapan Pengolahan Citra Digital

a. Setelah mendapatkan foto/gambar sampel greenbean kopi yang berformat .jpg, citra ini merupakan citra warna (RGB) dari greenbean tersebut.

b. Citra greenbean kopi yang masih berupa citra warna kemudian di lakukan cropping menjadi ukuran $32 \times 32$ px, hasil dari cropping tersebut kemudian diubah menjadi citra grayscale untuk memudahkan proses pengolahan citra selanjutnya. Pada tahap grayscalling dimana citra RGB dihitung nilai keabuan dari tiap pixel.

Tabel 2. Hasil Cropping greenbean kopi 32 × 32

\begin{tabular}{|l|l|l|l|}
\hline No & Depan & Belakang & Jenis Kopi \\
\hline 1 & 0 & & Arabika \\
\hline 2 & 0 & 0 & Arabika \\
\hline 3 & 0 & 0 & Robusta \\
\hline 4 & & 0 & Robusta \\
\hline
\end{tabular}

Tabel 3. Citra Grayscalling

\begin{tabular}{|l|l|l|}
\hline No & Depan & Belakang \\
\hline 1 & 8 & 8 \\
\hline 2 & 0 & 0 \\
\hline
\end{tabular}

Tabel 4. Citra Binner

\begin{tabular}{|l|l|l|}
\hline No & Depan & Belakang \\
\hline 1. & 0 & 0 \\
& 0 & 0 \\
\hline
\end{tabular}

c. Dalam proses pengolahan citra digital untuk menghitung ekstrasi ciri dari greenbean kopi arabika dan robusta dilakukan operasi 
morfologi yaitu proses erosi dan dilasi. Proses erosi dilakukan untuk menghilangkan atau mengurangi objekobjek yang tidak diperlukan dalam proses pengolahan selanjutnya. Struktur elemen pembentuk yang di pakai adalah matriks bujur sangkar dengan elemen yang bernilai 1.

d. Setelah dilakukan erosi proses selanjutnya adalah dilasi pada citra untuk mengembalikan objek yang hilang akibat proses dilasi, karena bagian objek (pikselpiksel) tersebut termasuk piksel-piksel yang akan dihitung untuk menentukan ekstrasi ciri. Perhitungan jumlah piksel objek dilakukan untuk jumlah piksel yang bernilai 1. Ekstrasi ciri yang akan dilakukan untuk mengetahui, panjang, tinggi, keliling, luas, rasio kebulatan perimeter dari setiap greenbean kopi.

Tabel 5. Ekstrasi ciri greenbean Robusta

\begin{tabular}{|c|c|c|c|c|c|c|c|}
\hline No & Nama File & $\begin{array}{l}\text { Lebar } \\
\quad(x) \\
\text { satuan } \\
\text { (piksel) } \\
\end{array}$ & $\begin{array}{c}\text { Tinggi } \\
(y) \\
\text { satuan } \\
\text { (piksel) }\end{array}$ & $\begin{array}{l}\text { Keliling } \\
\text { satuan } \\
\text { (piksel) } \\
\end{array}$ & $\begin{array}{c}\text { Luas } \\
\text { Permukaan } \\
\text { satuan } \\
\text { (piksel) } \\
\end{array}$ & $\begin{array}{c}\text { Prosentase } \\
\text { Kebulatan } \\
\text { satuan } \\
\text { (piksel) }\end{array}$ & \begin{tabular}{|c|} 
Perimeter \\
satuan \\
(piksel) \\
\end{tabular} \\
\hline 1 & IMG_7543.JPG & 7 & 10 & 27 & 56 & 96.48 & 1.5882 \\
\hline 2 & IMG_7540.JPG & 8 & 11 & 32 & 73 & 89.53 & 1.6842 \\
\hline 3 & IMG_7541.JPG & 8 & 11 & 33 & 74 & 88.34 & 1.7368 \\
\hline 4 & IMG_7537.JPG & 8 & 12 & 33 & 75 & 88.5 & 1.65 \\
\hline 5 & IMG_7538.JPG & 8 & 12 & 33 & 78 & 89.96 & 1.65 \\
\hline 6 & IMG_7535.JPG & 8 & 11 & 32 & 74 & 90.76 & 1.6842 \\
\hline 7 & IMG_7531.JPG & 8 & 11 & 32 & 74 & 90.76 & 1.6842 \\
\hline 8 & IMG_7528.JPG & 7 & 10 & 29 & 60 & 89.6 & 1.7058 \\
\hline 9 & IMG_7525.JPG & 8 & 11 & 30 & 65 & 90.71 & 1.5789 \\
\hline 10 & IMG_7526.JPG & 7 & 11 & 32 & 66 & 80.95 & 1.7777 \\
\hline & Rerata & 7.7 & 11 & 31.3 & 69.5 & 89.559 & 1.674 \\
\hline & & $\begin{array}{c}7 \\
\text { sampai } \\
8\end{array}$ & $\begin{array}{c}10 \\
\text { sampai } \\
12\end{array}$ & $\begin{array}{c}27 \\
\text { sampai } \\
33\end{array}$ & $\begin{array}{c}56 \\
\text { sampai } \\
78\end{array}$ & $\begin{array}{c}80.95 \\
\text { sampai } \\
96.48\end{array}$ & $\begin{array}{l}1.5789 \\
\text { Sampai } \\
1.7777\end{array}$ \\
\hline
\end{tabular}

Tabel 6. Ekstrasi ciri greenbean Arabika

\begin{tabular}{|r|l|r|r|r|r|r|r|}
\hline No & Nama File & \multicolumn{1}{|c|}{$\begin{array}{c}\text { Lebar } \\
(\mathrm{x}) \\
\text { satuan } \\
(\text { piksel) }\end{array}$} & $\begin{array}{c}\text { Tinggi } \\
(\mathrm{y}) \\
\text { satuan } \\
(\text { piksel) }\end{array}$ & $\begin{array}{r}\text { Keliling } \\
\text { satuan } \\
(\text { piksel) }\end{array}$ & $\begin{array}{c}\text { Luas } \\
\text { Permukaan } \\
\text { satuan } \\
(\text { piksel) }\end{array}$ & $\begin{array}{r}\text { Prosentase } \\
\text { Kebulatan } \\
\text { satuan } \\
\text { (piksel) }\end{array}$ & $\begin{array}{c}\text { Perimeter } \\
\text { satuan } \\
(\text { piksel) }\end{array}$ \\
\hline 1 & 13 & 16 & 43 & 156 & 100 & 1.4827 \\
\hline 2 & IMG_7117.JPG & 13 & 19 & 58 & 204 & 76.16 & 1.8125 \\
\hline 3 & IMG_7124.JPG & 13 & 18 & 51 & 196 & 96.64 & 1.6451 \\
\hline 4 & IMG_7123.JPG & 13 & 17 & 47 & 181 & 100 & 1.5666 \\
\hline 5 & IMG_7125.JPG & 15 & 20 & 51 & 230 & 100 & 1.4571 \\
\hline 6 & IMG_7127.JPG & 13 & 18 & 49 & 191 & 99.91 & 1.5806 \\
\hline
\end{tabular}

\begin{tabular}{|c|c|c|c|c|c|c|c|}
\hline No & Nama File & $\begin{array}{l}\text { Lebar } \\
\quad(x) \\
\text { satuan } \\
\text { (piksel) }\end{array}$ & $\begin{array}{l}\text { Tinggi } \\
\text { (y) } \\
\text { satuan } \\
\text { (piksel) }\end{array}$ & $\begin{array}{l}\text { Keliling } \\
\text { satuan } \\
\text { (piksel) }\end{array}$ & \begin{tabular}{|c|} 
Luas \\
Permukaan \\
satuan \\
(piksel) \\
\end{tabular} & $\begin{array}{c}\text { Prosentase } \\
\text { Kebulatan } \\
\text { satuan } \\
\text { (piksel) }\end{array}$ & $\begin{array}{l}\text { Perimeter } \\
\text { satuan } \\
\text { (piksel) }\end{array}$ \\
\hline 7 & IMG_7129.JPG & 13 & 22 & 56 & 233 & \begin{tabular}{|l|}
93.31 \\
\end{tabular} & 1.6 \\
\hline 8 & IMG_7130.JPG & 12 & 20 & 54 & 192 & 82.69 & 1.6875 \\
\hline 9 & IMG_7132.JPG & 13 & 18 & 50 & 195 & 97.96 & 1.6129 \\
\hline 10 & IMG_7133.JPG & 14 & 20 & 53 & 221 & 98.81 & 1.5588 \\
\hline \multicolumn{8}{|r|}{1.60038} \\
\hline & Rentang & $\begin{array}{l}13 \\
\text { Sampai } \\
15\end{array}$ & $\begin{array}{l}16 \\
\text { Sampai } \\
20\end{array}$ & $\begin{array}{l}43 \\
\text { Sampai } \\
58\end{array}$ & $\begin{array}{l}156 \\
\text { Sampai } \\
233\end{array}$ & $\begin{array}{l}76.16 \\
\text { Sampai } \\
100\end{array}$ & $\begin{array}{l}1.4571 \\
\text { Sampai } \\
1.8125\end{array}$ \\
\hline
\end{tabular}

\section{PENUTUP}

\subsection{Kesimpulan}

Berdasarkan hasil pengembangan dan pembahasan maka diperoleh kesimpulan sebagai berikut:

1. Tahapan proses pengolahan citra digital yang dimulai dari pengambilan gambar greenbean kopi, dilanjutkan dengan proses cropping gambar, tahap selanjutnya citra warna (RGB) diubah menjadi citra grayscale, pengubahan citra grayscale yang telah diperbaiki menjadi citra biner serta penerapan operasi morfologi yaitu erosi dan dilasi pada citra biner dapat digunakan untuk menghitung ekstrasi ciri jumlah piksel objek citra (greenbean kopi). Hasil dari proses sistem adalah membentuk perhitungan matematis untuk perhitungan, panjang, tinggi, luas, keliling, perimeter dan rasio kebulatan.

2. Hasil ekstrasi ciri yang diperoleh dari sampel greenbean kopi dengan rerata didapat lebar 7.7 piksel, tinggi 11 piksel, keliling 31.3 piksel, luas permukaan 69.5 piksel, prosentase kebulatan 89.559 piksel, dan perimeter 1.674 piksel dari greenbean kopi robusta. Sedangkan untuk greenbean arabika di dapat lebar 13.2 piksel, tinggi 18.8 piksel, keliling 51.2 piksel, luas permukaan 199.9 piksel, prosentase kebulatan 94.548 piksel, dan perimeter 1.60038 piksel dengan kesuluruhan data gambar yang diambil adalah 20 greenbean kopi.

\subsection{Saran}

Saran yang berkaitan dengan pengolahan citra digital untuk menghitung ekstrasi ciri greenbean kopi robusta dan arabika: 
1. Perlu adanya fitur tambahan dalam rasio kerampingan dalam ekstrasi ciri greenbean kopi robusta dan arabika.

2. Perlu adanya fitur tambahan ekstrasi ciri untuk greenbean pecah robusta dan arabika.

\section{DAFTAR PUSTAKA}

[1] H. Syahputra, F. Arnia, and K. Munadi, "Karakterisasi Kematangan Buah Kopi Berdasarkan Warna Kulit Kopi Menggunakan Histogram dan Momen Warna," J. Nas. Tek. Elektro, vol. 8, no. 1, p. 42, 2019, doi: 10.25077/jnte.v8n1.615.2019.

[2] S. N. Kane, A. Mishra, and A. K. Dutta, "Preface: International Conference on Recent Trends in Physics (ICRTP 2016)," J. Phys. Conf. Ser., vol. 755, no. 1 , 2016, doi: 10.1088/17426596/755/1/011001.

[3] B. D. Argo and M. Andreane, "Identfikasi Parameter Biji Dan Bubuk Kopi Robusta Menggunakan Machine Vision Dan Metode Artificial Neural Network (ANN)," J. Keteknikan Pertan. Trop. dan Biosist., vol. 5, no. 2, pp. 150-162, 2017.

[4] A. Mohan and S. Poobal, "Crack detection using image processing: $\mathrm{A}$ critical review and analysis," Alexandria Eng. J., vol. 57, no. 2, pp. 787-798, 2018, doi: 10.1016/j.aej.2017.01.020.

[5] Kadir, Abdul. Dasar Pengolahan Citra dengan Delphi. Yogyakarta : Andi Offset, 2013.

[6] Sutoyo. T, dkk, Teori Pengolahan Citra Digital. Yogyakarta: Andi Offset, 2009.

[7] J. Nader, Z. A., and B. Zahran, "Analysis of Color Image Filtering Methods," Int. J. Comput. Appl., vol. 174, no. 8, pp. 1217, 2017, doi: 10.5120/ijca2017915449.

[8] Yuhandri, S. Madenda, E. P. Wibowo, and karmila@staff gunadarma ac id Karmilasari, "Object feature extraction of songket image using chain code algorithm," Int. J. Adv. Sci. Eng. Inf. Technol., vol. 7, no. 1, pp. 235-241, 2017, doi: 10.18517/ijaseit.7.1.1479.

[9] R. Favoria Gusa, "Pengolahan Citra Digital Untuk Menghitung Luas Daerah Bekas Penambangan Timah," J. Nas. Tek. Elektro, vol. 2, no. 2, pp. 27-34, 2013, doi: 10.20449/jnte.v2i2.71.

[10] I. M. O. Widyantara, A. T. A. P. Kusuma, and N. M. A. E. D. Wirastuti, "Preprocessing Pada Segmentasi Citra Paru-Paru Dan Jantung Menggunakan
Anisotropic Diffusion Filter," Maj. IIm. Teknol. Elektro, vol. 14, no. 2, p. 6, 2015, doi: 10.24843/mite.2015.v14i02p02.

[11] Putra,Darma, Pengolahan Citra Digital. Yogyakarta : Andi Offset(penerbit andi), 2010

[12] Gonzales, R. C. and Woods R. E,. Digital Image Processing Second Edition. Beijing: Publishing House of Electronics Industry, 2002.

[13] Munir, Pengolahan Citra Digital Dengan Menggunakan Pendekatan Algoritmik. Bandung: Informatika, 2004. 